$07.2 ; 13.4$

\title{
Мощностные характеристики нитрид-галлиевых СВЧ-транзисторов на подложках кремния
}

\author{
() И.А. Черных ${ }^{1}$, С.М. Романовский르, А.А. Андреев ${ }^{1}$, И.С. Езубченко ${ }^{1}$, М.Я. Черных ${ }^{1}$, Ю.В. Грищенко ${ }^{1}$, \\ И.О. Майборода ${ }^{1}$, С.В. Корнеев ${ }^{2}$, М.М. Крымко ${ }^{2}$, М.Л. Занавескин ${ }^{1}$, В.Ф. Синкевич ${ }^{2}$ \\ ${ }^{1}$ Национальный исследовательский центр „Курчатовский институт“, Москва, Россия \\ ${ }^{2}$ AO „Научно-производственное предприятие „Пульсар“, Москва, Россия \\ E-mail: igor.chernykh@gmail.com
}

Поступило в Редакцию 10 октября 2019 г.

В окончательной редакции 26 ноября 2019г.

Принято к публикации 28 ноября 2019 г.

Методом газофазной эпитаксии из металлоорганических соединений выращены нитрид-галлиевые гетероструктуры на подложках кремния. На их основе созданы транзисторы с периферией $1.32 \mathrm{~mm}$. Мощность насыщения транзисторов в корпусе на частоте $1 \mathrm{GHz}$ составила 4 и $6.3 \mathrm{~W}$ при напряжениях питания 30 и $60 \mathrm{~V}$ соответственно. Максимальный коэффициент полезного действия стока составил 57\%.

Ключевые слова: транзистор с высокой подвижностью электронов, СВЧ-электроника, нитридная гетероструктура, нитрид галлия, полупроводниковые материалы, кремний.

DOI: 10.21883/PJTF.2020.05.49100.18068

Увеличение выходной СВЧ-мощности электронной компонентной базы определяет возможности новых систем связи и радиолокации. Благодаря своим уникальным физическим свойствам транзисторы на основе гетероструктур нитрида галлия $(\mathrm{GaN})$ обеспечивают наибольшие удельные мощностные характеристики. В подавляющем большинстве приборов используются СВЧ-транзисторы, созданные на подложках карбида кремния. Альтернативным подходом является активно развивающаяся технология $\mathrm{GaN}$ на кремнии, открывающая возможности удешевления производства за счет использования пластин диаметром $200 \mathrm{~mm}$ и более [1-3]. Примером выпуска серийной продукции по технологии $\mathrm{GaN}$ на кремнии являются СВЧ-транзисторы с удельной мощностью на миллиметр ширины затвора 4-6 W/mm и максимальной выходной мощностью дискретных транзисторов более $100 \mathrm{~W}$ в $L-, S$-диапазонах частот, выпускаемые компанией МАСОМ (США). Данные характеристики вполне сопоставимы с характеристиками транзисторов на подложках карбида кремния [4]. В России проводились попытки создания транзисторов по технологии $\mathrm{GaN}$ на кремнии. В работах [5,6] были получены эпитаксиальные гетероструктуры, созданы транзисторы и измерены их статические электрофизические параметры, однако ни малосигнальные, ни мощностные характеристики приведены не были. В НИЦ „Курчатовский институт“ в последние годы ведется работа по развитию собственной технологии $\mathrm{GaN}$ на кремнии (начиная с эпитаксиального роста нитридных соединений и заканчивая измерениями выходной мощности дискретных транзисторов). Ранее были представлены результаты исследований полученных транзисторов с удельной выходной мощностью $2 \mathrm{~W} / \mathrm{mm}$ при напряжении питания $20 \mathrm{~V}$ [7].
Целью настоящей работы является изучение характеристик СВЧ-транзисторов, созданных по технологии $\mathrm{GaN}$ на кремнии, а также разработка подходов для увеличения удельной мощности и повышения рабочего напряжения СВЧ-транзисторов. В работе представлены результаты развития технологии, позволившие достигнуть выходной мощности более $6 \mathrm{~W}$ при напряжении питания $60 \mathrm{~V}$.

Эпитаксиальная гетероструктура была выращена методом газофазной эпитаксии из металлоорганических соединений на установке AIXTRON 2600 G3 $11 \times 2^{\prime \prime}$. В качестве прекурсоров были использованы триметилалюминий, триметилгаллий и аммиак. В качестве газа-носителя использовался водород. Подложка $\mathrm{Si}(111)$ толщиной $500 \mu \mathrm{m}$ предварительно подвергалась химической обработке в водном растворе плавиковой кислоты, затем отжигалась в атмосфере водорода в течение $1 \mathrm{~min}$ при температуре $950^{\circ} \mathrm{C}$. Рост начинался с предварительной подачи триметилалюминия [8]. Далее формировался слой AlN, включающий „низкотемпературный“ (30 nm, $\left.795^{\circ} \mathrm{C}\right)$ и „высокотемпературный“ $\left(20 \mathrm{~nm}, 925^{\circ} \mathrm{C}\right)$ слои. Поверх AlN были выращены три слоя $\mathrm{AlGaN}$ с толщинами 270, 350 и $350 \mathrm{~nm}$ и процентным содержанием Al 80, 50 и 30\% соответственно. Давление в процессе роста слоев $\mathrm{AlN}$ и $\mathrm{AlGaN}$ поддерживалось равным $5 \mathrm{kPa}$. Канальный слой $\mathrm{GaN}$ толщиной $1.3 \mu \mathrm{m}$ формировался при температуре $930^{\circ} \mathrm{C}$ и давлении $10 \mathrm{kPa}$ с включением „низкотемпературной“ вставки AIN $\left(10 \mathrm{~nm}, 800^{\circ} \mathrm{C}\right)$. В завершение был выращен барьерный слой AlN толщиной $4.5 \mathrm{~nm}$. In situ контроль температуры подложки и толщин слоев проводился при помощи системы Laytec Epi TT.

Выбранная архитектура буферных слоев позволила накопить необходимые сжимающие напряжения в процессе роста слоев и сформировать гетерострукту- 

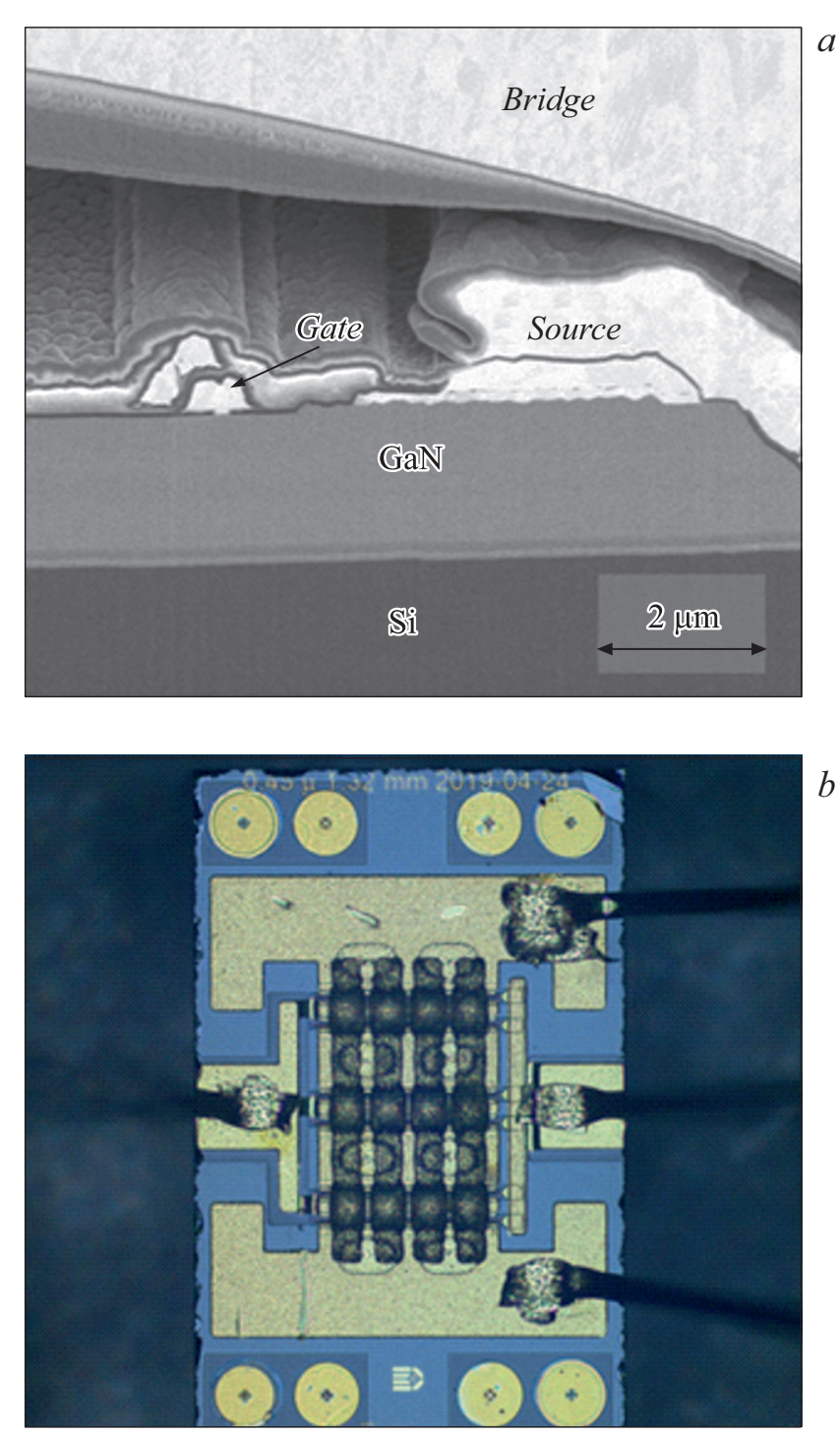

Рис. 1. $a-$ полученное с помощью растрового электронного микроскопа изображение поперечного среза транзистора; $b-$ транзистор в корпусе.

ры без трещин, пригодные для последующего процесса создания транзисторов с высокой подвижностью электронов. Кривизна структуры составляла не более $50 \mathrm{~km}^{-1}$. Концентрация и подвижность носителей заряда были определены методом ван дер Пау и составили $1.65 \cdot 10^{13} \mathrm{~cm}^{-2}$ и $920 \mathrm{~cm}^{2} /(\mathrm{V} \cdot \mathrm{s})$ соответственно, слоевое сопротивление гетероструктуры до пассивации было $412 \Omega / \square$.

Проект элементарной ячейки $\mathrm{GaN}$-транзисторного кристалла был разработан для напряжения питания $50 \mathrm{~V}$ с многопальцевым затвором шириной $1.32 \mathrm{~mm}$ и двумя уровнями металлизации. Проект и конструкционно-технологический запас позволяют формировать на кристалле несколько ячеек с целью увеличения мощности.

Для формирования кристаллов мощных GaN-транзисторов использовался технологический процесс, вклю- чающий в себя циклы формирования невжигаемых омических контактов с низким сопротивлением, плазмохимического травления меза-изоляции, формирования затворной металлизации с длиной затвора $0.45 \mu \mathrm{m}$ путем последовательного выполнения электронно-лучевой литографии и напыления Ni/Au. Пассивация транзисторных структур осуществлялась путем плазмохимического осаждения $\mathrm{SiN}_{x}$. При создании структур были реализованы блоки формирования двухуровневой металлизации, позволившей создать многопальцевые затворы с „воздушными мостами“ и полевыми электродами затвора и истока (рис. $1, a$ ). Детальное описание маршрута создания транзисторов было приведено в работе [7]. После формирования кристаллов выполнялась гальванизация обратной стороны пластины без ее утонения, далее резка на кристаллы и корпусирование.

Измерения статических параметров проводились на зондовой станции Cascade PM5 с помощью двухканального источника-измерителя Keithley 2636B при комнатной температуре на постоянном токе.

Монтаж транзисторов в корпуса КT-44B (SOT-467C) осуществлялся на установке West Bond 7327C в AO „НПП „Пульсар“. Разварка золотой проволокой выполнялась на полуавтоматической установке West Bond 353637F. Вид транзистора в корпусе приведен на рис. 1, $b$. После монтажа кристаллов в корпуса транзисторов энергетические характеристики измерялись с помощью специализированного стенда в АО „НПП „Пульсар“. Стенд включал в себя генератор сигналов Agilent N5181A, усилитель РМ12-C8-1 (ЗАО „Микроволновые системы) и измеритель мощности Кеysight N1918A. Для согласования импеданса транзистора с импедансом линии $(50 \Omega)$ использовались многозвенные цепи согласования, расположенные на внешних платах. Критерием оптимизации процесса согласования являлось получение максимальной выходной мощности. Выходная мощность измерялась на частоте $1 \mathrm{GHz}$. Длина импульса питания составляла $10 \mu \mathrm{s}$ при скважности $Q=100$. Данный режим измерений использовался для минимизации эффекта разогрева транзистора и его влияния на выходные характеристики. Для расчета КПД транзистора измерялся импульс тока стока.

Слоевое сопротивление гетероструктуры после пассивации определялось методом длинной линии, оно составило $350 \Omega / \square$. Сопротивление невжигаемых контактов было менее $0.15 \Omega \cdot \mathrm{mm}$. Ток насыщения транзистора на миллиметр ширины затвора был равен $900 \mathrm{~mA} / \mathrm{mm}$ (рис. 2,a), максимальная крутизна транзистора составила $210 \mathrm{mS} / \mathrm{mm}$, напряжение отсечки составило $-5 \mathrm{~V}$. Пробивное напряжение транзистора определялось трехзондовым методом при напряжении на затворе $V_{g}=-8 \mathrm{~V}$. Остаточный ток стока при напряжении вплоть до $V_{d s}=160 \mathrm{~V}$ при комнатной температуре не превышает $I_{d}=0.5 \mathrm{~mA}$ (рис. $2, b$ ). Следует отметить изменение темпа роста утечки при напряжении $V_{d s}=110 \mathrm{~V}$. По всей видимости, это связано с электрическим пробоем в эпитаксиальную вставку AlN. Уровень 

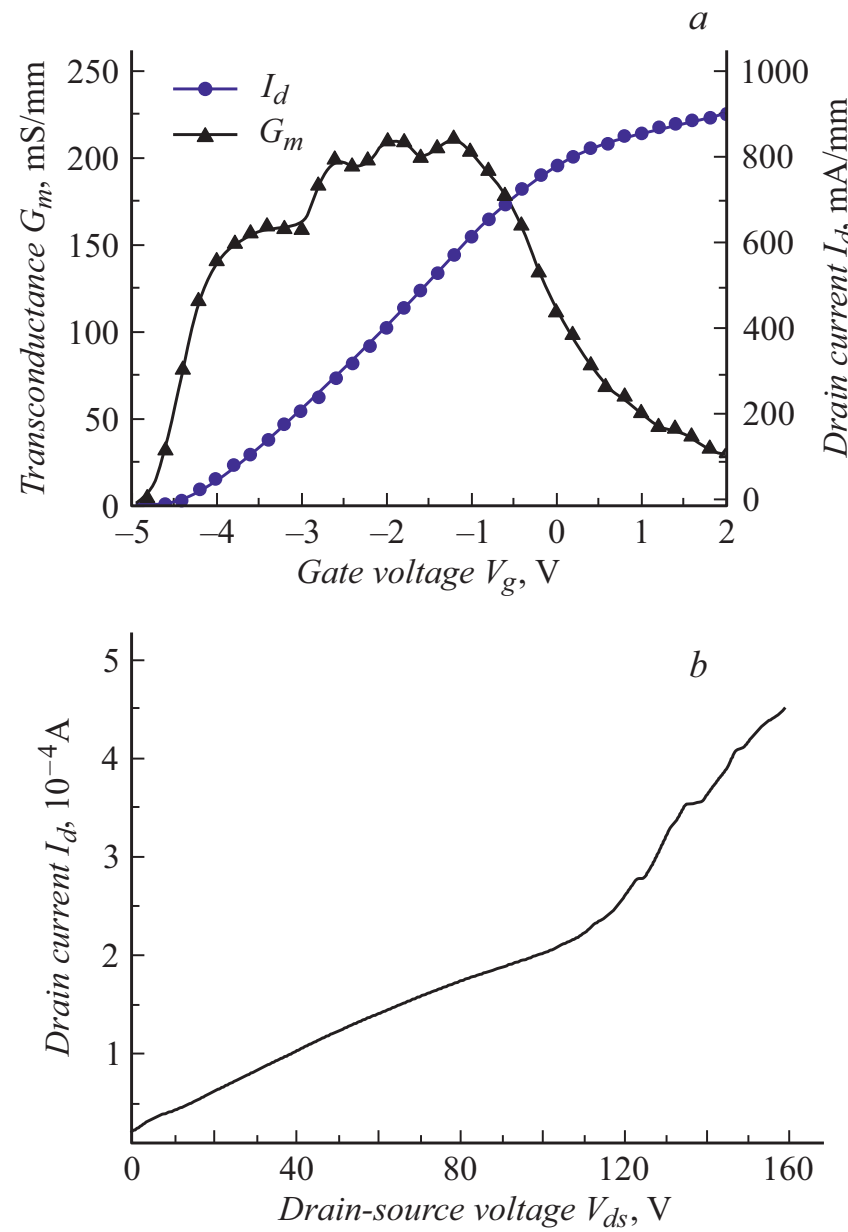

Рис. 2. Статические характеристики транзистора с шириной затвора $1.32 \mathrm{~mm}$. $a-$ стоко-затворная характеристика транзистора; $b-$ зависимость тока стока от напряжения сток-исток при $V_{g}=-8 \mathrm{~V}$.

утечки не превышает соответствующее значение на схожих транзисторах производства компании МАСОМ, в частности на транзисторе NPTB00004A.

Мощностные характеристики транзистора приведены на рис. 3. При увеличении входной мощности наблюдается монотонное снижение усиления, при достижении входной мощностью значения $P_{\text {in }}=100 \mathrm{~mW}$ уровень усиления $G_{p}$ снижается с 21 до $16 \mathrm{~dB}$. КПД транзистора растет с повышением входной мощности до значения 44\%. Мощность насыщения транзистора при напряжении питания $30 \mathrm{~V}$ была равна $P_{\text {sat }}=4 \mathrm{~W}$, при этом компрессия составила $5 \mathrm{~dB}$ (рис. $3, a$ ). Рост КПД транзистора и спад $G_{p}$ с повышением входной мощности обусловлен тем, что транзистор переходит из линейной в нелинейную область работы. В нелинейной части происходит заход рабочей точки в область перенапряжения и отсечки, что приводит к росту КПД транзистора. C целью получения максимальной входной мощности в процессе измерения динамических параметров осуществлялась подстройка цепей согласования и режима смещения транзистора по затвору. При небольшой входной мощности транзистор работал в классе $A$, а при увеличении входной мощности транзистор работал в классе $A B$, в котором $G_{p}$ меньше, а КПД транзистора больше, чем в классе $A$. При увеличении напряжения питания от 30 до $60 \mathrm{~V}$ мощность насыщения монотонно растет до значения $6.3 \mathrm{~W}$ (рис. $3, b$ ). Максимальный коэффициент полезного действия стока составил 57\% при напряжении сток-исток $15 \mathrm{~V}$. Влияние напряжения питания на динамические параметры оценить сложнее, поскольку здесь наравне с увеличением доли рассеиваемой в тепло мощности начинают играть роль ловушки и поверхностные состояния в кристалле. Работы по данному направлению ведутся, для этого разрабатывается специальная оснастка, позволяющая измерять
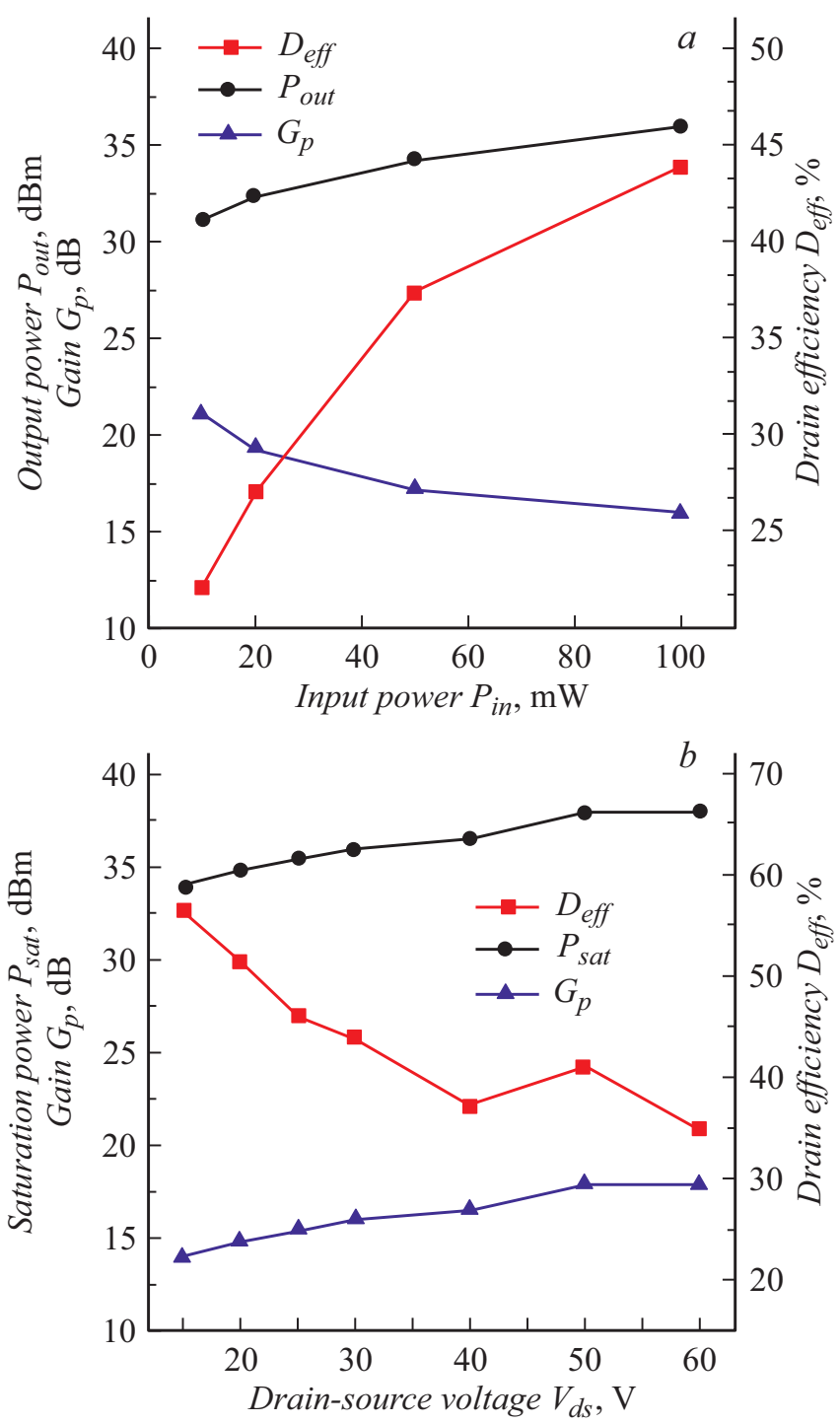

Рис. 3. Мощностные характеристики транзистора с шириной затвора $1.32 \mathrm{~mm}$. $a$ - зависимости выходной мощности, КПД транзистора и усиления от входной мощности при напряжении питания $30 \mathrm{~V} ; b$ - зависимости мощности насыщения, КПД транзистора и усиления от напряжения питания при $P_{\text {in }}=100 \mathrm{~mW}$. 
вольт-амперные характеристики транзистора в коротких импульсах (200 ns).

Статические характеристики транзисторов были схожи с данными нашей предыдущей работы [7], однако ключевыми моментами исследования стали совершенствование эпитаксиальных гетероструктур и использование полевого электрода стока, что позволило повысить рабочее напряжение (до $60 \mathrm{~V}$ ) и выходную мощность.

Таким образом, в работе на подложках кремния выращены нитрид-галлиевые гетероструктуры, на их основе созданы транзисторы с периферией $1.32 \mathrm{~mm}$ и изучены статические и мощностные характеристики. Измеренная мощность насыщения транзисторов в корпусе на частоте $1 \mathrm{GHz}$ составила $6.3 \mathrm{~W}(4.7 \mathrm{~W} / \mathrm{mm})$ при напряжении питания $60 \mathrm{~V}$. Максимальный коэффициент полезного действия стока составил 57\%. Полученные результаты соответствуют мировому уровню для аналогичных транзисторов на подложках кремния.

\section{Финансирование работы}

Работа выполнена при финансовой поддержке Национального исследовательского центра „Курчатовский институт“ (приказ от 25.06.2019 г. № 1359).

\section{Конфликт интересов}

Авторы заявляют, что у них нет конфликта интересов.

\section{Список литературы}

[1] Chen K.J., Häberlen O., Lidow A., Tsai C., Ueda T., Uemoto Y., $W u$ Y. // IEEE Transact. Electron Dev. 2017. V. 64. N 3. P. 779-795. DOI: 10.1109/TED.2017.2657579

[2] Cheng J., Yang X., Sang L., Guo L., Zhang J., Wang J., He C., Zhang L., Wang M., Xu F., Tang N., Qin Z., Wang X., Shen B. // Sci. Rep. 2016. V. 6. P. 23020 (1-7).

DOI: $10.1038 /$ srep23020

[3] Semond F. // MRS Bull. 2015. V. 40. P. 412-416. DOI: $10.1557 / \mathrm{mrs} .2015 .96$

[4] Quay R., Schwantuschke D., Ture E., Raay F., Friesicke C., Krause S., Müller S., Breuer S., Godejohann B., Brückner P. // Phys. Status Solidi A. 2018. V. 215. N 9. P. 1700655 (1-7). DOI: 10.1002/pssa.201700655

[5] Алексеев А.Н., Александров С.Б., Бырназ А.Э., Великовский Л.Э., Великовский И.Э., Красовицкий Д.М., Павленко М.В., Петров С.И., Погорельский М.Ю., Погорельский Ю.В., Соколов И.А., Соколов М.А., Степанов М.В., Ткаченко А.Г., Шкурко А.П., Чалый В.П. // Письма в ЖТФ. 2008. T. 34. B. 7. C. $58-64$.

[6] Арендаренко А.А., Орешкин В.А., Свешников Ю.Н., Цыпленков И.Н. // Изв. вузов. Материалы электронной техники. 2015. Т. 18. № 1. С. 5-15.
[7] Андреев А.А., Грищенко Ю.В., Езубченко И.С., Черных М.Я., Колобкова Е.М., Майборода И.О., Черных И.А., Занавескин М.Л. // Письма в ЖТФ. 2019. Т. 45. В. 4. C. 52-54. DOI: 10.21883/PJTF.2019.04.47340.17567

[8] Chernykh M.Y., Ezubchenko I.S., Mayboroda I.O., Zanaveskin M.L. // J. Cryst. Growth. 2019. V. 507. P. 200204. DOI: $10.1016 /$ j.jcrysgro.2018.11.020 